\title{
Commercialization of nanotechnology in last decade in India: A review
}

\author{
Rahul Goswami* Piyush Singhal and Vineet Kr. Shrivastav ${ }^{\#}$ \\ Department of Mechanical Engineering, GLA University, \#17 km stone, NH\#2 Mathura, U.P., India \\ Email:*rahul.goswami@gla.ac.in, \# vineet.shrivastav_me12@gla.ac.in
}

Nanotechnology is not a discrete technology or an industry sector. It simplify refers to a range of technologies that operates at a nano-scale. At nano-scale some material gains new characteristics and functionalities that can be used for innovative applications in myriad sectors.

Because of change in characteristics and functionalities of materials at nano-scale, much research has been done since the initiative taken in 1980's in the research field of nanotechnology across the globe. Different studies shows that the global market and the impact of nanotechnology in key functional components by the year 2015 to be in the range of \$1 to \$2.6 trillion with requirements of 2 million workers and about three times many jobs in supporting activities (Figure 1).

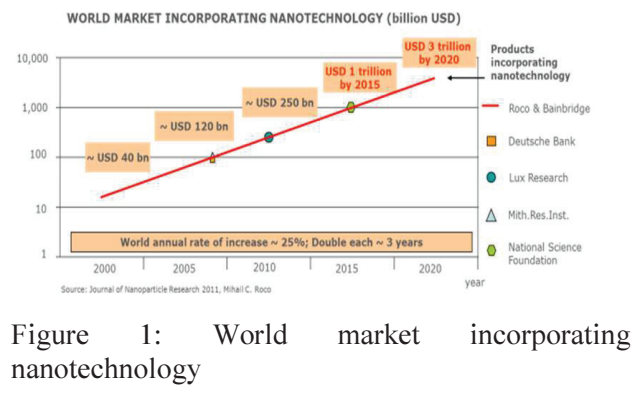

\section{Nanotechnology: India Scenario}

India takes nanotechnology as a distinct area of research started with NSTI (Nano Science and Technology Initiative) in 2002-2007 with an allocation of rupees 60 crores (approx. USD 12 million). NSTI was initiated and implemented by DST. NSTI helped in establishing units for developing research excellence in nano science, centres for nanotechnology each aimed at application development and two national instrumentation/characterisation. Figure 2 summarizes the major initiatives taken by India in nanotechnology during 2001-2012.

Though India is a late comer to nanotechnology, but now a decade after the initiative taken by Indian government, research activities in nanotechnology has increased and is improving continually with performance in sub sectors and by selected researchers and all fourteen national institutions, including seven IITs and ten universities supported by NSTI.

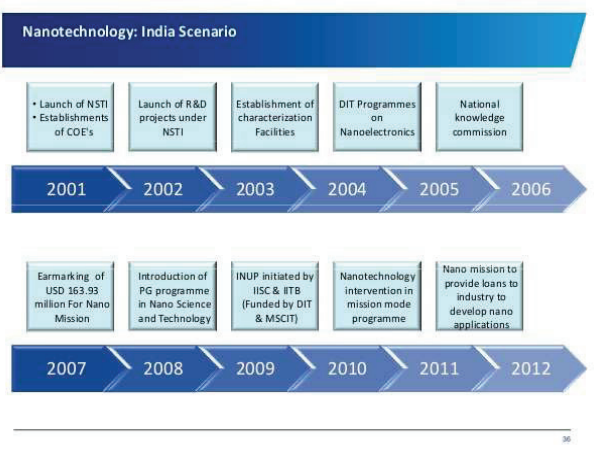

Figure 2: Major initiatives taken by India in nanotechnology during 2001-2012

Objective: In this paper, we define commercialization, present current strategies and methods. Here we examine and reviewed the current decisions and action about the challenges of nanotechnology commercialization in India and assess the path for future commercialization.

Keywords: Commercialization, challenges in commercialization, nanotechnology.

\section{References}

1. Mihail C Roco., Journal of nanoparticle research( 2011).

2. Vibrant-gujarat-summit-profile-forbiotechnology-and-nano-technology. 